\title{
NASKAH SERAT WULANG SUNU SEBUAH SASTRA DIDAKTIS: KAJIAN
}

\section{FILOLOGI}

\author{
Kamidjan \\ Universitas Negeri Surabaya \\ Email: kamidjan.unesa@gmail.com
}

\begin{abstract}
Abstrak
Naskah Serat Wulang Sunu, merupakan salah satu karya sastra Jawa yang berisi ajaran moral. Oleh para peneliti karya itu digolongkan ke dalam sastra didaktis moralistis. didaktis moralistis. Dari segi isi jkarya itu dinilai cukup bagus, karena ajaran yang tertuang di dalamnya bersifat universal. Oleh sebab itu ia beberapa kali disalin. Sebagai bukti di Museum Sanabudaya Yogyakerta terdapat dua naskah, dalam bendel naskah berbeda. Selain itu di Pacitan juga terdapat naskah yang berjudul sama meskipun isinya lebih panjang. Adapun isi yang tertuang di dalamnya antara lain: (1) anak cucu dan kerabatnya diwajibkan berbakti kepada kedua orang tua, terutama ibu. (menjaga silaturahmi antar keluarga di lingkunga kraton Surakarta sifatnya wajib. Hubungan kekeluargaan diibaratkan sebuah pucung, dan hubungan antara singa dan hutan yang saling menjaga, menjunjung tinggi kejujuran, menjauhi perbauatan tercela yang berkaitan dengan ma lima, dan menegndalikan nafsu. Dalam diri manusia dikuasai oleh empat orang raja. Mereka adalah ratu Mutmainah, ratu Supiah, Raja Amarah dan Raja Aluamah. Mereka menggambarkan nafsu manusia. Nafsu bukan untuk dihilangkan melainkan dikendalikan. Ratu Mutmainah bertugas mengendalikan raja-raja tersebut.
\end{abstract}

Kata Kunci: Naskah, Serat Wulang Sunu, Sastra Didaktis

\begin{abstract}
The text of Serat Wulang Sunu, is one of Javanese literary works containing moral teachings. By the researchers the work was classified into the moralistic didactic literature. didactic moralistic. In terms of jkarya content is considered quite good, because the teachings contained in it are universal. Therefore he was copied several times. As evidence in the Sanoguan Museum of Yogyakerta there are two manuscripts, in different manuscripts. Also in Pacitan there is also a script titled the same although the content is longer. The contents contained in it, among others: (1) children and grandchildren and their relatives are obliged to devote to both parents, especially mothers. (keeping the relationship between families in Surakarta palace circle is mandatory.) A kinship is like a pucung, and the relationship between lion and forest is mutually guarded, upholding honesty,
\end{abstract}


avoiding disgraceful deeds associated with ma five, and defying the lust In man is dominated by four kings, the queen of Mutmainah, the queen of Supiah, the King of Anger and the King of Aluamah, who portrayed the human desires, the lust not to be eliminated but controlled, Queen Mutmainah was in charge of the kings.

Keywords: Script, Warak Sunu Fiber, Didaktis Literature

\section{PENDAHULUAN}

Sastra Jawa menduduki tempat istimewa di antara sastra nusantara. Karena karya sastranya telah muncul sejak abad ke 9 M (Zoetmulder, 1983:8). Sastra yang muncul pada saat itu digolongkan ke dalam sastra Jawa Kuna. Karya sastra Jawa yang berkembang hingga abad ke 15 dan banyak mendapat pengaruh India. Periode tersebut mencapai puncak kejayaannya pada zaman Kediri. Pada zaman tersebut raja dan pujangga bekerja sama menghasilkan karya sastra. Raja mengemukakan ide, oleh pujangga dituangkan dalam karya sastra. Pujangga yang mendapat kesempatan menggubah karya sastra atas perintah sang raja, ia mendapatkan anugrah yang tak ternilai karena mendapat kepercayaan. Kepercayaan itu oleh Zoetmulder (1983) disebut imamagi sastra. Sedangkan C C Berg (1985) menyebut sanmatta. Bila karya itu mendapat perhatian disebut prasasti, dan bila dibaca karya itu oleh raja disebut Santasmrti. Penghargaan yang luar bbiasa.

Periode Sastra Jawa Kuna, zaman Kediri memegang peranan penting di bidang kesastraan. Zaman itu sastra Jawa mengalami zaman keemasan, diprakarsai oleh Darmawangsa Teguh. Beliau yang memerintahkan untuk menjawakunakan Ramayana, Mahabharata dan purana. Sastra Jawa Kuna yang berisi ajaran agama. Keberhasilan tersebut terulang pada zaman Surakarta awal, yang disebut dengan istilah zaman ranaisanse sastra Jawa. Kala itu di istana raja dan pujangga menciptakan karya sastra. Diawali oleh pangeran Karanggayam, di kraton Pajang, menggubah kitab Nitti Sruti, (Poerbatjaraka, 1967). Hingga zaman modern, kraton merupakan penghasil karya sastra yang 
bermutu tinggi. Karya-karya itu sebagian besar bersifat keagamaan, didaktis moralistis dan sejarah. Di zaman modern fungsi istana di bidang olah sastra terfokus pada pencatatan berbagai peristiwa yang terjadi di istana, misalnya pernikahan, jumenengan (penobatan) dan kematian, diabadikan dalam genre babad. Sebagai catatan sejarah, yang sangat penting bagi kehidupan kraton.

Istana sebagai pusat kegiatan olah sastra tampak di Kasunanan Surakarta disebut pujangga dalem. Selain Yasadipura I, dan II, serta R. Ng. Ranggawarsita, sebagai pujangga dalem, para raja di Kasunanan Surakarta dan Pura Mangkunagaran sebagian besar aktif dalam penggubahan karya sastra. Mereka membangun karya sastra sebelunya agar dapat dimanfaatkan mengingat bahasa Jawa Kuna sudah tidak dikuasai oleh masysrakat dan untuk menghindari kepunahan, disebut karya bangunan. Selain itu mereka juga mencipta karyakarya baru, digolongkan ke dalam karya yasan. Salah satu di antara mereka yang cukup produktif adalah Sri Pakubuwana IV. Beliau menggubah Serat Wulang Sunu.

Sri Pakubuwana IV, dikenal dengan nama Ingkang Sinuwun Bagus. Beliau lahir pada hari Kamis Wage tanggal 18 Rabingulakhir, bertepatan atau tanggal 2 September 1768, diberi nama Bandara Raden Mas Gusti Sumbadya, putra Sri Pakubuwana III dengan Kanjeng Ratu Kancana. Putri Tumenggung Wirareja, abdi dalem Bupati Gedong Tengen, bernama Ki Jagaswara. Beliau dinobatkan menjadi raja pada hari Senin Pahing 28 Besar Jimakir 1714 (29 September 1788), bergelar Ingkang Sinuhun kangjeng Susuhunan Pakubuwana Senapati ing Alaga Abdurrahman Sayidin Panatagama IV. Beliau wafat pada hari Senin Pahing 23 Besar Alip 1747 (1 Oktober 1820). Menjabat selama 33 tahun. Beliau aktif menggubah karya sastra. Adapun karyanya adalah, Serat Wulang Reh, Serat Wulang Sunu, Serat Wulang dalem, Serat Bratasunu, Serat Wulang Putri, Serat wulang Tatakrama, Serat Panji Raras, Serat Panji Sekar, Serat Panji Dhadhap dan serat Panji Blitar (Darusuprapta, 1992: 25-27). 
Seiring dengan perkembangan zaman, huruf Jawa semakin terpinggirkan. Untuk mempertahankan nilai-nilai yang terkandung dalam naskah-naskah ada usaha pengalihtulisan naskah-naskah berbahasa Jawa, baik yang berhuruf Jawa maupun Arab Pegon. Usaha tersebut bertujuan untuk melestarikan isi yang terkandung di dalam naskah, sehingga bisa disebarluaskan ke masyarakat. Sebab nilai-nilai yang tersebut masih bisa dimanfaatkan. Terutama nilai-nilai yang bersifat adiluhung. Tulisan ini mencoba membahas salah satu sastra Jawa karya Sri Paku Buwana IV, berjudul Serat Wulang Sunu.

\section{Moral dalam Sastra}

Pigeaud (1967:2), menjelaskan bahwa secara umum sastra Jawa dibedakan menjadi 4 kelompok, yaitu (1) agama dan kesusilaan, (2) Sejarah dan mitologi (3) susastra dan (4) bunga rampai. Berdasarkan pembagian tersebut, agama dan kesusilaan menduduki urutan pertama. Secara hirarkhis pembagian kelompok pertama menunjukkan betapa pentingnya karya-karya tersebut bagi masysrakat. Ajaran agama dan etika dibutuhkan oleh umat manusia untuk menjalani hidup di dunia. Agama digunakan untuk bekal hidup di alam baka dan dunia fana. Betapa pentingnya agama dalam kehidupan manusia. Sementara itu untuk menopang kehidupan dalam masysrakat diperlukan etika, agar terjadi harmonisasi kehidupan yang damai.

Sebagai dokumen sosio budaya masyarakat, sastra memiliki fungsi sesuai dengan amanatnya. Seperti sifat sastra, dulce et utile. Bahwa sastra itu indah dan bermanfaat. Indah berfungsi untuk hiburan. Sedangkan bermanfaat karya sastra dapat dipakai sebagai sarana pendidikan, terutama generasi muda yng sedang mencari jati diri. Salah satu karya sasstra piwulang Serat Wulang Sunu, gubahan Sri Pakubuwana IV.

Sesuai dengan judulnya, Serat Wulang Sunu, termasuk sastra piwulang. Di dalamnya memuat ajaran moral dari ayah kepada putra-putrinya. Karya itu 
digubah dalam bentuk tembang macapat dengan bahasa yang indah. Selain bahasanya indah, isinyapun cukup komunikatif, dan mudah dipahami. Nilai-nilai moral yang tertuang di dalamnya dapat dijadikan sarana pendidikan moral. Walaupun digubah di istana ternyata isinya bersifat umum, bisa digunakan oleh siapapun dan di manapun.

Moral selalu berkaitan dengan nilai. Tetapi nilai tidak selalu berkaitan dengan moral. Moral identik dengan etika. Etika merupakan pamikiran yang sistematis tentang moral. Oleh sebab itu dalam kajian ini moral disejajarkan dengan nilai etika. Etika merupakan salah satu ilmu, dan merupakan bagian dari filsafat. la bersifat praktis, normatif dan fungsional. Dengan demikian etika berfungsi dalam kehidupan sosial masyarakat sehari-hari.. Etika menjadi azas yang menjiawai norma-norma dalam mmasyarakat dan memberikan penilaian dalam tingkah laku manusia (Salam, 2000:14).

Berdasarkan penilain, moral dibedakan menjadi moral keagamaan dan moral sosial. Nilai moral keagamaan mengacu pada keyakinan setiap umat, terhadap keberadaan sang pencipta sehingga merasa memiliki kewajiban untuk mejalankan perintah dan menjauhi larangan-Nya. Niali moral sosial, menunjukkan bahwa umat manusia juga disebut makhluk sosial. Maksudnya manusia hidup dalam masyarakat membutuhkan bantuan dan pertolongan orang lain.

Nilai moral dalam sastra umumnya disampaikan secara tersirat, melalui struktur, dalam tema cerita atau amanat. Dalam sastra Jawa terdapat karya yang demgan sengaja menyajikan etika. Seperti dikemukakan oleh Pigeaud. Hal ini menunjukkan betapa pentingnya karakter dalam kehidupan manusia dalam menjalani hidup. Etika diaktualisasikan dalam kehidupan sehari-hari, sebagai sarana menata tingkah laku manusia dalam menjalani hidup. Agar terjadi keseimbangan dengan harapan dapat hamamayu hayuning bawana. Dalam kehidupan bermasyarakat umat manusia dapat menerapkan norma yang 
berlaku, sebagai tatanan sopan santun dan tata krama demi terciptanya tatanan sosial saling menghormati dan saling menghargai.

Moral merupakan sebuah kata yang mengatur tingkah laku manusia dalam menjalani hidup dalam masyarakat. Poespoprodjo (1999:118) menjelaskan bahwa moralitas dimaknai sebagai aturan tingkah laku, yang berkaitan dengan nilai benar atau salah. Moral memiliki makna baik buruknya tingkah laku manusia. Manusia dianggap bermoral bila tindakannya sesuai dengan tuntutan dan norma dalam masyarakat. Dewasa ini pemerintah sedang menggalakkak pendidikan karakter, melalui berbagai jalur.

\section{Serat Wulang Sunu dan Penyalinannya}

Berdasarkan keterangan di atas, bahwa salah satu karya Sri Pakubuwana IV, berjudul Serat Wulang Sunu. Sesuai dengan tradisi naskah, dalam pendekatan filologi, naskah sering diturun atau disalin. Hal ini juga terjadi pada naskah Serat Wulang Sunu. Terbukti di museum Sanabudaya terdapat 2 versi Serat Wulang Sunu. Keduanya dalam kelompok piwulang dan suluk. Bendel berkode No. P. 29, PB B 30 berjudul Kempalan Serat-Serat Piwulang, terdiri atas 11 naskah. Serat wulang Sunu terdaftar pada urutan nomor 9. Dalam bendel itu dijelaskan bahwa karya tersebut gubahan Kasan Bunawi atas perintah Pakubuwana IV (Behrend, 1990: 463). Sedangkan bendel berkode No. P 162, SK 144 berjudul Serat WarniWarni, terdiri atas 30 naskah. Pada bendel tersebut Serat Wulang Sunu, terdaftar pada urutan nomor 5, (Behrend, 1990: 522). Berdasarkan data tersebut, terdapat 5 varian Serat Wulang Sunu. Dari ke lima karya itu, mungkin yang tertua atau original, yang terdapat dalam catatan Darusuprapta. Dalam hal tersebut penulis belum mengecek ke perpustakaan Kraton, Surakarta, Pura Mangku Nagaran maupun Radyapustaka. Kemungkinan besar diperpustakaan tersebut terdapat naskah Serat wulang Sunu mengingat penulisan karya tersebut dilakukan di kraton tersebut, pada masa penulis memegang tahta kerajaan. 
Dalam teori filologi, terdapat beberapa salinan naskah dengan berbagai tujuan. Baried (1994) menjelaskan bahwa penyalinan naskah memiliki beberapa tujuan. Di antaranya, seseorang ingin memiliki naskah tersebut, menjaga agar terhindar dari kepunahan, atau seseorang meminta agar menyalin untuk kepentingan pribadi. Dengan adanya

Serat Wulang Sunu yang terdapat dalam catatan Darusuprapta (1992:25) berbeda dengan yang disimpan di perpustakaan Museum Sonobudoyo, Yogyakarta. Perbedaan itu tampak pada jumlah pupuh. Catatan Darusuprapta terdiri atas 5 pupuh (Dhanghanggula, 16 bait, Asmaradana, 20 bait, Sinom 15 bait, Pangkur 20 bait dan Kinanthi 23 bait). Sementara itu koleksi Perpustakaan museum hanya 4 pupuh. Dhandhanggula, 12 bait, Asmaradana, 16 pada, Sinom 16 bait dan Pangkur 20 bait.

Sesuai dengan judulnya, Serat Wulang Sunu, menjabarkan nasihat orang tua kapada anaknya. Dalam hal ini nasihat itu disampaikan oleh Sunan Pakubuwana IV, raja Kasunanan Surakarta Hadiningrat kepada putra-putrinya. Dari segi etimologis, kata wulang berarti wuruk, pitutur (nasihat), (Prawiro Atmodjo 1987:431). Kata sunu berarti: anak. Adapun dasanama anak antara lain: anak, siwi, putra, yoga, atmaja, dll. Dengan demikian wulang sunu mengandung arti pitutur, piwulang, atau nasihat kepada anak.

Kajian dalam tulisan ini menggunakan naskah koleksi Museum Sonobudoyo bendel P. 29, PB B 30 berjudul Kempalan Serat-Serat Piwulang. Salah satunya berjudul Serat Wulang Sunu. Sri Pakubuwana IV seorang raja dan pujangga. Sebagai seorang raja ia sangat peduli terhadap budaya. la seorang tokoh dan pendidik. Kepedulian itu tampak dalam kiprahnya di bidang olah sastra. Selain menggubah fiksi yang bersumber dari cerita Panji beliau menggubah karya-karya didaktis, seperti telah disebut di atas. Karya-karya tersebut oleh Behrend (1990: 522) digolongkan ke dalam sastra didaktis. Salah satu di antaranya Serat Wulang Sunu. Dalam katalog tersebut terdapat dua versi. 
Sementara itu di Pacitan ada sebuah naskah, milik mbah Ranu (Vivin, 2010). Berdasarkan pengamatan penulis, koleksi tersebut berupa bendel, terdiri atas Serat Wulang Sunu, Serat Wulang Reh, dan Kidung Reksawedha. Naskah Pacitan dan koleksi Museum Sanabudaya, terdapat perbedaan. Naskah koleksi perpustakaan museum Sanabudaya diawali (P.1.1.1) Wulang Sunu sinawung artati..., sedangkan naskah Pacitan diawali (P.1.1.1) Wulang Sunu kang sinawung gendhing, .... Selain itu jumlah pupuh juga berbeda. Naskah Sonobudoyo berjumlah 4 pupuh, semenrata itu naskah Pacitan terdiri atas 5 pupuh. Bila dikonfirmasikan dengan keterangan Darusuprapta (1992:25), naskah Pacitan tersebut salinan gubahan Pakubuwana IV. Sedangkan naskah Sonobudoyo yang tergabung dalam Kempalan Serat-Serat Piwulang, karya Kasan Bunawi, atas perintah Pakubuwana IV.

Karya-karya Sri Paku Buwana IV sebagian besar digolongkan ke dalam sastra piwulang. Karya sastra yang khusus berisi ajaran moral. Pada awalnya karya-karya itu ditujukan kepada putra-putrinya. Tetapi karena isinya cukup baik dan bersifat universal, karya-karya tersebut diangkat agar bisa dimanfaatkan oleh masyarakat. Berbagai ajaran terdapat di Serat Wulang Sunu. Di antaranya patuh dan berbakti kepada orang tua, utamanya ibu. Durhaka kepada orang tua, tidak akan mendapatkan pengampunan dari Allah Swt. Jangan berbuat jahat, bertindak sesuai tata krama dan sopansantun. Di depan orang tua harus bersikap sabar. Ajaran selanjutnya adalah kerukunan dalam keluarga diutamakan. Jangan sampai bertengkar dengan keluarga.

Berdasarkan keterangan Darusuprapta (1992: 25), Serat Wulang Sunu merupakan salah satu gubahan Sri Paku Buwana IV. Sesuai dengan teori filologi, bahwa naskah-naskah nusantara sering diturun dan disalin, sehingga terdapat satu judul yang terdiri atas beberapa naskah atau varian. Tetapi tulisan ini bukan untuk membandingkan varian-varian dan merunut silsilah naskah, melainkan membahas isi Serat Wulang Sunu. Pembahasan didasarkan pada koleksi 
Museum Sanabudaya Yogyakarta dalam bendel No. P 162, SK 144 Serat WarniWarni, terdiri atas 30 teks. Pada bendel tersebut Serat Wulang Sunu, terdaftar pada urutan nomor 5 terdiri atas 4 pupuh tembang macapat, yaitu Dhandhanggula 12 bait, Asmaradana 16 bait, Sinom, 16 bait dan Pangkur 20 bait.

Pengarang menggubah Serat Wulang sunu, dalam bentuk pitutur luhur, nasihat orang tua kepada anak pasti memiliki tujuan. Beliau ingin menanamkan etika agar putra-putrinya memiliki tata krama. Ajaran itu dituangkan dalam bentuk tembang macapat agar dapat dipahami.dan diaplikasikan dalam kehidupan sehari-hari. Ternyata karya tersebut mendapat apresiasi dari para peneliti sehingga menyebar ke masyarakat secara luas.

\section{Serat Wulang Sunu Sebuah Sastra Piwulang}

Ajaran dalam Serat Wulang Sunu dituangkan dalam 4 pupuh tembang macapat. Setiap pupuh mengandung ajaran sesuai dengan watak tembang yang digunakan. Pupuh 1, tembang Dhandhanggula, memiliki watak luwes, cocok untuk segala suasana. Oleh pengarang dipakai untuk menyampaikan nasihat agar putra-putrinya berbakti kepada orang tua, terutama ibu. Karena peran seorang ibu dalam mendidik dan mendewasakan anaknya menjadi tanggung jawabnya. Jerih payah seorang ibu sejak mengandung hingga anaknya menikah tak pernah putus, bahkan doanya sepanjang hayat. la tidak pernah menegluh, dan menjalankan dengan ikhlas.

Surga di bawah telapak kaki ibu. Sebuah pernyataan, yang berkaitan dengan eksistensi yang menjunjung tinggi harkat dan martabat perempuan, khususnya ibu. Ungkapan yang sangat bijak. Ungkapan yang menjunjung tinggi keberadaan seorang perempuan yang dibutuhkan oleh anak-anaknya. la harus dihormati. Kita berbakti. Bakti seorang anak kepada ibu terdapat dalam sastra Jawa Kuna, Kitab Agastyaparwa. Bagi mereka yang berbakti dan mengagungkan keberadaannya, akan mendapatkan pahala. . Kutipan berikut: . 
Hana pwa wwang maradin mawak suci mamata, sadakala, bhakti mebu kalingan ika: mahapawitra ika ling sang hyang agama (Gonda, 1934)

\section{Terjemahannya:}

Ada orang yang senantiasa berbuat kebaikan, berwatak suci, menurut kitab suci: Berbaktilah kepada ibu, karena orang yang demikian sangat mulia, menurut agama ......

Ibu siap mengemban tugas yang sangat berat. la mendidik, mengasuh dan menyayangi. Ibu bagaikan bumi. la sabar, bagaikan ibu pertiwi. Diperlakukan apapun ia menerima. Bumi melahirkan flora fauna untuk kebutuhan umat manusia. Sedangkan ibu melahirkan putra-putri yang soleh dan bijaksana untuk menjaga ketertiban dunia demi ketenteraman dan kedamaian.

Dalam Serat Wulang Sunu terdapat 4 pitutur luhur (nasihat) pokok, yang wajib ditaati oleh putra-putri penggubah, mencakup (1) bakti seorang anak kepada orang tua terutama ibu, (2) persaudaran dan silaturahmi dalam kelurga harus tetap dijaga, (3) sarik agung, pantangan yang harus dijaga dengan ketat adalah ma lima, dan (4) mengekang hawa nafsu. Penjabarannya sebagai berikut:

\section{Berbakti kepada Orang Tua}

Berbakti kepada orang tua terdapat dalam beberapa agama di Idonesia. Karena orang tua yang menyebabkan kita ada. Beliau pula yang menyayangi, mendidik dan mengasuh. Jasa orang tua terhadap anaknya tidak bisa dibalas dengan apa pun. Oleh sebab itu kita tidak boleh durhaka. Kisah kasih orang tua, oleh penggubah disampaikan pada Pupuh i, bait 1-8. Intinya sebagai berikut:

1) Wulang sunu sinawung artati/kang pinurwa tataning ngawula/suwita ing wong tuwane/sami dipunmituhu/ing pitutur kang muni tulis/sapa nora anut sak ujar ing tutur/ tan wurung kasurang-surang/donya ngakir tan sande manggih bilaheng/ siniksa dening Yang Sukma//

2) Lamun sira iya anglampahi/ ing pitutur ingkang muni nglayang/pesthi becik tebasane/ bekti ing rama ibu/ pan purwane sira udani/ karya becik lan ala 
saking bapa biyung / duk sira maksih jejabang, tiyang ngira kelangkung lara prihatin rumeksa marang sira//

3) Nora eca dhahar lawan guling/ibunira rumeksa ing sira/mangan sekul uyah bahe/ tan ketang wejah pluntur/basan nyakot bathok upama/ ben dina mring patirtan/ wuwung lawan bekung/pilis singgul linakonan/labetipun rumeksa sira duk alit/ mulane den rumangsa//

Kutipan di atas, menjelaskan bahwa seorang anak wajib berbakti kepada kedua orang tua. Terutama kepada ibu. Pada kutipan di atas dijelaskan bagaimana kondisi seorang ibu ketika sang anak masih kecil. Apa pun dilakukan demi anak. Minum jamu, makan seadanya. Ke sungai mencuci pakaian, oleh sebab itu berbaktilah.

Sang raja memaparkan ajaran itu rupanya mengambil dari ajaran agama. Berbakti kepada orang tua terutama ibu, juga terdapat dalam ayat suci, Q.S Luqman (31) ayat 14: yang terjemahannya:

Dan Kami perintahkan kepada manusia (berbuat baik) kepada dua orang ibu- bapanya; ibunya telah mengandungnya dalam Keadaan lemah yang bertambah- tambah, dan menyapihnya dalam dua tahun. bersyukurlah kepadaKu dan kepada dua orang ibu bapakmu, hanya kepada-Kulah kembalimu.

Selain kutipan di atas, dalam Islam juga terdapat hadids nabi yang diriwayatkan oleh Bukhori, yang mdan bapak. Berdasarkan uraian di atas mewajibkan setiap anak berbekti kepada orang tua, terutama ibu. Kitab Agastyaparwa, ayat suci Al Qur'an dan hadis nabi membuktikan hal itu. Bahwa seseorang yang durhaka kepada orang tua hidupnya akan sengsara.

\section{Menjaga tali Silaturahmi dalam Seluarga}

Pupuh II, Asmaradana, sang raja memberikan nasihat (anak, cucu, cicit, canggah dan wareng) agar tetap menjaga silaturahmi antar keluarga. Dalam sebuah keluarga jangan sampai terjadi percekcokan. Memalukan. Bahwa mereka yang berselisih dengan keluarga, tidak akan menemukan kebahagiaan. Hidupnya tidak tenang, tidak pernah merasa tenteram. la tidak rela bila anak cucunya 226 | ISSN: 22477-5150 http://journal.unesa.ac.id/index.php/jpi 
bertengkar dan berselisih paham. Bila dalam keluarga tidak akur bagaimana dengan tetangga. Kutipan berikut:

1) Lawan malih wekas mami, anak putu buyut ingwang, miwah canggah wareng ingong, poma padha estokena/ing pitutur kang arja, aja na tukaran padu, mungsuhan kelawan kadang.

2) Dahat ingsun tan nglilani sujalma laku dursila/cungkrah lawan sudarane temahan tan manggih arja, lan tipis kang sarira/ wong liyan kathah kang purun, amejanani mring sira (SWS.II.1-2).

Inti dari kutipan di atas adalah bahwa sang raja mengharapkan keluarganya mematuhi nasihatnya. Beliau tidak rela bila dalam keluarganya terjadi pertengkaran. Sebaiknya saling menjaga silaturahmi. Sebab pertengkaran tidak membuahkan kerukunan, dan kedamaian. Bila sesama keluarga tidak mau akur, kpercayaan masyarakat semakin menipis, dan mencibir. Pepatah mangan ra mangan nek ngumpul, merupakan refleksi keakraban dalam sebuah keluarga. Pepatah tersebut menyarankan bahwa menjaga silaturahmi dalam keluarga merupakan salah satu sarana untuk mempererat tali persaudaraan. Hal itu sampai sekarang masih terpiara. Walaipun di era global. Mereka urban, mereka meluangkan waktu dan tetap menyempatkan diri untuk silaturahmi. Karena fasilitas semakin terpenuhi. Setidaknya masih terdapat beberapa peristiwa yang dianggap sangat tepat untuk berkumpul. Misalnya, mudik saat Idul Fitri, hajatan dan lelayu. Kesempatan itu dimanfaatkan. Bahkan ada lagi yang menyempatkan diri untuk berkumpul dengan kaluarga, pada tradisi nyadran. Nnyekar bersama pada bulan Sa'ban atau Ruwah untuk menyambut datangnya bulan suci Ramadhan.

Perselisihan dalam keluarga diibaratkan buah pucung. Ketika masih muda biji pucung (kluwak) menyatu. Tetapi setelah tua berserakan, menjadi bumbu masak, pindhang. Pindang adalah salah satu masakan orang Jawa, terbuat dari buah kluwih, dengan bumbu santan dan kluwak. Masakan tersebut merupakan salah satu syarat dalam kirim doa, seribu hari meninggalnya seseorang. Namun 
dengan perkembangan zaman masakan itu sudah tidak dtgunakan lagi, sekarang kluwak untuk bumbu rawon dan brongkos. Kutipan berikut:

3) Dipunkumpul sira sami, ingkang gecul tekadira, lah den ngrompol ing bandhola poma iku den estokna, yen sira nedya arja, aja na kawong ran pucung, anom kumpul tuwa pisah.

4) Yen koyoa pucung ugi, selawasira ing gesang, dadi wong pindangan bahe, dudu watek ing sujana, lawas sira neng dunyan, jalma kang wus umup anom kumpul tuwa tan pisah.

Kutipan di atas menunjukkan bahwa bila kita ingin hidup bahagia sebaiknya jangan seperti buah pucung. Penulis berharap kepada anak cucunya, jangan sampai terjadi percekcokan antar keluarga yang dapat menimbulkan perpecahan. Bagi penulis pertengkaran dalam keluaraga, merupakan perbuatan yang nistha. Bahkan orang lain dan tetangga mencibir. Nasihat tersebut juga disampaikan dalam Serat Wulang Reh, pupuh IX, tembang Pucung, berikut:

Kamulane kaluwak nom-nomanipun, pan dados setunggal, pucung arane puniki, bareng tuwa kaluwake pisah-pisah.

Den budiya, kepriye ing becikipun, aja nganti pisah, kumpule kaya enome, enom kumpul tuwa kumpul kang prayoga.

Aja kaya kaluwak enome kumpul, basa wis atuwa, ting salebar dhewedhewe, nora wurung bakal dadi bumbu pindhang.

Wong sadulur nadyan sanak dipunrukun, aja pisah ing samubarang karsane, padha rukun dinulu teka prayogi (P ix. 1-4). .

Baik Serat Wulang Sunu maupun Serat Wulang Reh, keduanya karya Sri Pakubuwana IV, beliau seorang raja yang sangat peduli di bidang pendidikan. Keepdualian itu dituangkan ke dalam karyakarya yang oleh par peneliti digolongkan ke dalam Sastra Piwulang. Karya-karya itu antara lain: Serat Wulang Putri, Serat Piwulang Dalem Pakubuwana IV, dsb.

Pepatah Jawa mengatakan crah agawe bubrah, rukun agawe santosa. Makna pepatah tersebut bahwa perpecahan akan merusak tali persaudaraan 
dalam keluarga, yang merusak hubungan keluarga. Beliau mengharapkan agar keakraban tetap terjaga, hubungan kekeluargaan di kraton Surakarta Hadiningrat. Rukun agawe santosa memiliki makna bahwa kebersamaan akan menimbulkan kekuatan dan ksesejahtraan. Hal ini mengacu kepada sifat gotong royong dalam masysrakat. Sebuah masalah akan terasa berat bila ditanggung sendiri. Akan terasa ringan bila ada seseotrang yang mau memberikan solusi.

Di era global di mana seseorang lebih mengutamakan materi, maka hubungan kekeluargaan pun terabaikan. Harapan penulis ternyata hampa. Karena tahta, saudara kandung yang sebaiknya dibina menjadi taruhan. Karena di kraton Surakarta terjadi dualisme pemerintahan. Perebutan kekuasaan pun tidak bisa dihindari (.....). Kedua bersaudara yang seharusnya saling menjaga martabat keluarga karena tahta, pecah. Karena mereka merasa memiliki hak naik tahta.

Perpecahan dan pertengkaran dalam keluarga oleh sang raja diibaratkan buah pucung. Semasa masih muda bijinya menyatu, terpaut erat satu dengan yang lain. Tetapi setelah tua, biji buah bertebaran, manjadi kluwak. Salah satu jenis bumbu dalam makanan tradisional Jawa. Salah satu di antaranya pindang, sejenis sayur yang bumbuny menggunakan kluwak. Di Jawa Tengah kluwak digunakan untuk bumbu brongkos, sedangkan di Jawa Timur untuk bumbu rawon.

Pandangan itu juga disampaikan dalam Serat Wulang Reh, pupuh IX, Pucung, terdiri atas 23 bait. Dalam karya itu kerukunan dalam keluarga dibaratkan buah pucung. Sebaiknya semasa muda hingga masa tua hidup guyup rukun, saling membantu dalam berebagai masalah keluarga. Tetapi ajaran itu dalam Serat wulang Reh lebih longgar. Saudara tua, harus bisa menjaga (momong) adik-adiknya tanpa pilih kasih. Semua saudara diperlakukan sama. Bila mereka bersalah sebaiknya ditegur. Sehingga adik-adiknya dapat menaruh rasa hormat dan segan. Mereka saling menghormati. 


\section{Pekerjaan Yang Sebaiknya Ditekuni}

Pupuh III, Serat Wulang Sunu menyajikan berbagai macam pekerjaan. Menurut sang raja di dunia ini ada tiga macam pekerjaan, yang pantas dilakukan. Pekerjaan tersebut adalah: maca, macul dan ngaji. Membaca bukan berarti membaca buku atau koran. Melainkan pekerjaan yang berkaitan dengan administrasi. Sebagai abdi negara. Kedudukan meningkat, menjadi priyayi. Karena berhubungan dengn sesama umat, kita harus menghargai sesama, jangan sampai membuat sakit hati. Bila menekuni pekerjaan macul, harus tinggal di desa mengolah sawah unuk memenuhi kebutuhan masyarakat.

Umat manusia sebaiknya memilih salah satu. Boleh juga ketiganya dilakukan. Apapun pekerjaan yang dipilih harus ditekuni, agar mendapatkan barokah. Kutipan berikut:

1) Wonten malih kang winarna, pratingkah ing nambut kardi, kathahe tigang prakara, kang prayoga den antepi maca, macul, lan ngaji puniku karya linuhung sami karya klahiran, iku kalebu utami, pira bara punika kangge sedaya.

2) Apan ta salah satunggal, poma antepana kaki, kelamun sira menawa, kang ngantepi karya ngaji, den bisa banting ragi, aneng ngarsaning gurumu, yen oleh marmaning Yang, kasinungan bisa ngaji, apesipun benjang dadi modin desa.

3) Yekti alus pundhakira, nora nganti den pikuli, poma-poma wekasing wang, aja na kaleru tampi, pami wibawa mukti, apan saking ing Hyang Agung, aja ambeg kuwawa, pasraha marang Hyang Widi, den rumangsa kamukten murah ing sukma.

Bila menekuni pekerjaan ngaji, menekuni bidang agama. Setidaknya bisa menjadi modin atau naib. Hasilnya lumayan, bisa mencukupi kebutuhan keluarga, dan khalal. Bila pekerjaan itu dijalankan dengan ikhlas, bisa diangkat menjadi hakim (hakim agama). Sebuah kedudukan yang cukup tinggi di istana. Namun demikian ada syarat yang harus dilakukan yaitu harus adil dan jujur. Jangan memihak pada yang salah dengan alasan apapun ( PIII. 5-6) berikut: 
Cinatur wiryaning jalma/ ing ngantepi karya ngaji /yen jinunjung drajat ira/ dening Hyang kang maha suci pan sira dadi kakim saya wuwuh ingkang lungguh amengku penaiban/ marentah ing ketib modin dadi saya agung ing rijekinira//

Nanging poma wekas ing wang/ lamun sira dadi kakim dipunjejeg kukum ira/kelawan dipun wirangi lan malih wekas mami yen sira jeneng ke kukum/ ywa budi sesanakan/ den kenceng kukume ngadil apan sira kinarya wakiling nata.

Diceritakan, bahwa insan yang mulia, bila memilih pekerjan di bidang agama, derajadnya diangkat oleh Allah Swt. Lebih-lebih bila menjadi hakim, naib atau modin, semakin lancar rejekinya. Pesan beliau, bila menjadi hakim harus menegakkan keadilan, jangan berhubungan dengan orang yeng sedang berperkara. Keadilan harus tetap ditegakkan. Karena hakim mewakili Tuhan dalam memutuskan perkara. Oleh sebab itu jangan menerima suap.

\section{Menjunjung Tinggi Kejujuran}

Dalam sastra Jawa Kuna, karya sastra yang bernafaskan Hindu dan Bhudha banyak yang mengangkat kejujuran dan kebenaran. Misalnya dalam Agastyaparwa, diceritakan bahwa seseorang yang tidak jujur. Sedangkan Slokantara, menjelaskan bahwa seseorang yang menggali 100 buah sumur, lebih mulia yang menggali sebuah telaga. Orang yang menggali 100 telaga masih kalah dengan seseorang yang memberikan ilmu pengetahuan kepada sesama. Itu pun masih kalah dengan mereka yang menyerahkan anak gadis bila sudah ada yang melamar. Namun demikian semua itu masih lebih baik mereka yang menjunjung tinggi kejujuran dan kebenaran (Suprayitno, 1983)

Dalam ajaran Islam bekerja adalah ibadah. Oleh sebab itu harus ikhlas. Keikhalan dalam menjalankan pekerjaan harus didukun dengan kejujuran dan menegakkan kebenaran. Sebagai seorang raja Pakubuwana IV, memberikan contoh kepada kerabatnya agar selalu menjunjung tinggi kejujuran dan 
kebenaran. Nasihat itu dituangkan pada Serat Wulang Sunu, yang dikaitkan dengan pemilihan pekerjaan yang ditekuni. Dalam karya itu, dijabarkan pada tiga macam pekerjaan yang rawan dengan kebohongan. Yaitu pedagang, blantik (makelar dan kemasan). Beliau mengatakan bahwa:

Dene ingkang karya dagang/ apa dene karya blantik/ agung gawe palacidra/marang sesamining jalmi dagangan kang pengaji seteng den tawakaken sasuku amrih pajenge kathah/pan iku cegahen kaki tan brekati gorohi samining jalma//

Wondene karya kemasan/tan ana jalma binatin/apan namung bedhang ngira/kang binatin trusing ngati liyane iku sami den krenah panjupukipun/langkung wasis ing jalmi yen ta rah darbeking jalma ya kemasan maling datan pababahan//

Ewata mengkono uga/ yen sira temen ing batin/tan ana ingkang cinacat/kemasan lan dagang blantik/dadi karya utami yen sira temen ing kalbu/nanging ingkang wus kaprah/kemasan lan dagang blantik/agung gawe tetiga cidra ing jalma// (SWS. 18-20).

Kutipan di atas menjalaskan ba hwa bila seseorang memilih pekerjaan tersebut, kejujuran harus tetap dijunjung tinggi. Bekerja adalah ibadah. Pekerjaan itu menjadi sarana untuk meemnuhi kebutuhan keluarga. Oleh sebab itu agar keluarga mendapatkan barokah, dalam pelaksanaannya harus dilandasi dengan keikhlasan. Agar tetap mendapatkan rejeki yang khalal, sebaiknya dilandasi kejujuran. Jangan sekali-kali menipu dengan cara apapun. Sebab di dunia ini yang rawan dengan kebohongan, adalah pedagang, makelar, kemasan (pembuat perhiasan emas). Pedagang dan makelar, sering berbohong tentang harga dagangan. Sedangkan kemasan, sering memalsukan kadar emas. Dalam hal ini sang raja mengibaratkan maling tanpa babahan (pencurian tersamar), dengan tipu daya. Bila ketiga pekerjaan itu ditekuni, junjunglah kejujuran. Sebab pekerjaan itu rawan dengan kebohongan (cidra ing jalma), menipu sesama umat.

\section{Nilai Moral pada Diri Pribadi}

Pupuh IV Serat Wulang Sunu, menyajikan nasihat bahwa dalam diri umat manusia dikuasai oleh 4 nafsu, yang diibaratkan raja yang berkuasa. Nafsu 
tersebut bukan untuk dibrantas melainkan dikendalikan. Sebab tanpa nafsu hidup manusia terasa hambar dan tidak ada gairah atau nglokro). Nasihat tersebut berkaitan dengan tingkah laku sehari-hari. Meliputi perbuatan baik dan buruk. Salah satu nasihat yang berkaitan dengan perbuatan tercela dan betentangan dengan agama oleh sang raja disebut cacat agung. Artinya perbuatan itu menjadi larangan agama dan norma, dituangkan pada kutipan berikut:

Wonten ingkang winarnaha/ cacat agung anglangkungi kathahe wolung prakara/ bedhok nyolong nyidra resmi/nginum sajeng muroni maling nayap begal ngecu nora kena tinrajang/pan iku cegah ing widi sekar sinom salin pangkur kang gumanya//(P. III.21)

Kutipan diatas menjelaskan bahwa dalam masysrakat ada perbuatan yang nenjadi larangan agama dan masyarakat. Perbuatan itu di bidang Kamtibmas disebut pekat atau penyakit masyarakat. Yang termasuk golongan itu adalah: bedhog (mencuri binatang piaraan), mencuri, selingkuh, minuman keras, mencuri jemuran, begal, merampok, adalah larangan agung, yang harus dihindari. Dalam masyarakat Jawa kebiasaan itu disebut ma lima. Selain dalam Serat Wulang Sunu ajaran tersebut juga terdapat dalam beberapa karya sastra Jawa. Misalnya Serat Ma Lima, Mim pitu, Serat Wasita Dyah Utama, Serat Harda Mudha (Kamidjan: 2012).

Selain itu nafsu manusia oleh sang pujangga juga dituangkan pada pupuh 4, sebanyak 20 bait. Dalam pupuh itu dijabarkan bahwa dalam diri umat manusia dikuasai oleh 4 orang raja. Dua orang ratu, mereka adalah Ratu Supiah dan Ratu Mutmainah. Dua orang lainnya, Raja Amarah dan Raja Aluamah, (p.IV.1-2). Kutipan berikut:

1) Lawan malih kawruhana/ ratu papat manganing jroning jisim/sekawan watakanipun/ana becik lan ala/ raja estri ingkang kalih raja jalu kang priya jejuluk ira/ raja luamah nerpati// 
2) Satunggal raja Amarah/ ingkang ngestri jejuluk ing nerpati Dewi Supiyah puniku/kang satunggal tengeran/retna Dewi Mutmainah ayu punjul/busana cuweni pethak/sang dyah karepeke [...] widi//

Dalam falsafah Jawa, keempat raja tersebut merupakan sifat manusia. Supiah merupakan penggambaran nafsu seksual dan berbagai macam keinginan manusia. Pada hal tidak semua keinginan bisa terpenuhi. Yang lebih penting kebutuhan yang harus dipenuhi. Mutmainah sebagai penetral nafsu lain. Raja amarah mengambarkan sifat manusia yang memiliki nafsu amarah. Sedangkan aluamah adalah sifat serakah. Sifat mutmainah digambarkan sebagi lambang kesucian. Pakaian serba putih, taat beragama, berbakti kepada kedua orang tua, dan senantiasa berbuat baik. la dibantu oleh Patih Sabar, anak buahnya pemberani dan namun sopan, ucapannya lemah lembut. Pintu gerbang berjendela 2, yaitu lubang hidung. latananya di jantung, (p.IV. 3-7). Kutipan berikut:

3) Miwah bekti mring panutan/myang mring ibu rama bekti sru wedi ing kahutaman rahayu sang retna langkung rahab/patih ira dipati sabaranipun/tumenggung anteng sentana/wonten warganira malih//

4) Dyannarya sura jatmika/ raden panji jinem wecanang dening ingkang dadya korenipun/ mas rongga catur seca/amung gansal reh-e kulawarganipun/ nenem mengabe [..] itrima/ iku punakawan kasih//

5) Aneggih negaranira prabu mutmainah kelangkung wingit/winasta keraton jantung kelangkung dening pelag/ lamun arsa miyos kusumaning ngayu ing grana dedalan ira/wiwara nira sang dewi//

Kutipan di atas menggambarkan sifat Dewi Mutmainah. Sifat baik manusia, yang selalu menjadi penetral dari perbuatan manusia yang menyimpang dari norma dan agama. Oleh sebab itu iadigambarkan sebagai orang yang suci, berpakaian putih bersih. Patih yang membatu bernama Sabar, tumenggung anteng jatmika, ucapannya lemah lembut. Kerajaannya di jantung. Tempat yang sangat dalam. Didukung pintu gerbang bila ia ingin keluar melalui lubang hidung, kita tahu di antara panca indera kita yang paling jujur adalah hidung. Mata, 
telinga dan mulud, bisa bohong, namun hidung tidak pernah bohong. Apa yang dialami diungkapkan secara jujur.

Ratu Supiah menggambarkan nafsu birahi manusia. Sang raja digambarkan, berpakaian kuning. la sangat anggun. Tetapi sifatnya benyak keinginan. Oleh sebab itu pintu keluarlewat mata. Kita tahu bahwa umat manusia selalu menginginkan sesuatu yang indah. Oleh sebab itu bia ia melihat sesuatu yang indah, mulut berdecak kagum, dan ingin memiliki. Berkaitan dengan sifat tersebut dihubungkan dengan: jatuh cinta pada pandangan pertama. Demikian iuga bila menginginkan sesuatu diawali dengan pandangan pertama (P.IV. 6-7), berikut:

6) Karsane retna supiyah/ sru penginan melikane kepati lenggah ing keraton pusuh busana sutra jenar/ lamun miyos ing netra dedalanipun/ mulane jalma manungsa/yen kala mongsa ningali//

7) Marang ing paesan dun [...]/manah ira iya banget kepengin/ wani kuping gotanipun/nenggih dewi supiyah/pramilane anak putu buyut ingsun/miwah canggah wareng ing wang den sami prayitneng batin//

Tokoh lain, yang bersemayam dalam diri kita adalah raja Amarah. Dalam Serat Wulang Sunu, terdapat pada P.IV. 11-16. Dijelaskan bahwa raja Amarah, gagah perkasa, dalam menghadapi musuh. Bala tentaranya sangat kuat. Punggawanya pun gagah berani. Patihnya bernama Patih Lanas, raden Ladak, calak lengus, perkataannya lancang.

Penammpilannya sangat ekstrim. Pakaiannya serba merah, punggawanya bernama Angkuh, adul-adul, jail methakil, riya sumengah, kibir, takabur, brangasan dan kusut. Uraian tersebut, sebenarnya menggambarkan sifat manusia yang berkaitan dengan sifat amarah. Oleh sebab itu sifat-sifat yang terdapat diri manusia yang sedang marah. Sifat itu antara lain angkuh, jail methakil, sumengah (sombong dan merasa lebih), takabur, lanas( mudah marah) dan brangasan, mudah marah. Dalam keadaan marah seseorang kadang-kadang tidak bisa mengandalikan ucapan dan sikap. Bahkan cenderung cengkiling 
(menganiaya). Sifat-sifat tersebut terdapat dalam diri kita. Sifat itu sebaiknya dikendalikan. Jangan dipiara dalam hati. Berdasarkan pengamatan, tidak pernah ada orang yang tidak pernah marah. Namun demikian sifat ini harus dikendalikan.

Dalam budaya Jawa terdapat sifat yang melukiskan seseorang yang sedang marah, atau candrane wong nesu, (Ciri orang yang sedang marah) meliputi: jajabang mawinga-winga, kumedud padoning lathi, netra andik angatairah dan lir sinebit talinganir (Padmosoekotjo. S 1952). Maksudnya orang yang sedang marah, dadanya panas, bibir rasanya ingin mengumpat, matanya merah bagaikan berdarah dan telinganya panas, bagaikan dijewer. Itulah sifat amarah dalam diri manusia.

Raja amarah bertahta dalam daging. la keluar melalui telinga. Hal tersebut sesuai dengan kondisi diri manusia. Bila mendengar sesuatu yang tidak berkenan dihati, amarahnya muncul, tanpa dikomando. Dada terasa panas, mata merah dan kata-kata kotor keluar tanpa kontrol.

Raja, lain yang bersemayam dalam diri manusia adalah Raja aluamah (P.IV. 19-24). Beliau bertahta dalam dalam perut. Bila keluar lewat pintu gerbang, mulut. la sangat kuat. Sang raja tidak memiliki banyak punggawa, hanya tiga orang. Seorang patih bergelar Kala Dremba (banyak makan), ngangsa-angsa (ambisius), tumenggung bergelar Kalamurka. la sanagt sakti. Ditambah seorang punggawa, demang sungkan doyan. Ciri raja Aluamah, ia banyak makan, dan tidur. Sebagai lambang keserakahan, ia dilukiskan berbusana serba hitam. Oleh sebab itu bila manusia kekurangan makan (lapar), apa pun dilakukan. Untuk mengendalikan sebaiknya cegah dhahar, guling dan banyak dhikir. Maksudnya sebagai umat manusia sebaiknya mengurangi makan dan tidur,dan memperbanyak dhikir.

\section{SIMPULAN}


Uraian di atas dapat disimpulkan bahawa Naskah Serat Wulang Sunu yang dianalisis dalam tulisan ini koleksi Museum Sana Budaya, Yogyakarta. Karya teersebut merupakan salah satu karya sastra Jawa Klasik yang mengetengahkan ajaran-ajaran Sri Pakubuwana IV kepada kerabatnya. Ajaran iitu dituangkan dalam bentuk tembang macapat, terdiri atas empat pupuh, (1) Dhandhanggula 12 bait, (2) Asmaradana 16 bait, (3) Sinom 16 bait dan Pangkur 20 bait.

Sesuai dengan judulnya Wulang Sunu, tetu saja isinya berupa ajaran atau piwulang. Karena isinya cukup baik, maka karya itu beberapa kali disalin sehingga timbul beberapa versi atau varian. Dalam hal in penulis dapat menginventarisasi empat naskah, yaitu: dua naskah koleksi Museum Sanabudaya, Yogyakarta, 1 naskah bersasal dari Pacitan dan satu naskah, kolejsi pribadi (dalam bentuk foto copy).

Ajaran yang tertuang di dalamnya antara lain: berbakti kepada orang tua terutama kepada ibu. Sebab ibu yang melahirkan kita. la mngasuh, mendidik dan menyayangi kita. Dalam sebuah keluarga jangan terjadi percekcokan karena salah paham. Silaturahmi dalam kekuarga sebaiknya tetap dijaga. Pertengkaran dalam keluarga diibaratkan buah pucung. Semasa masih muda mereka bersatu setelah tua mereka berpencar. Selain diibaratkan buah pucung, juga identik singa dengan hutan. Keduanya harus saling menjaga. Agar tidak dijarah oleh manusia.

Tuhan menyediakan berbagai macam lapangan kerja, untuk memberikan rejeki kepada umatnya. Dari berbagai macam itu dirangkum menjadi 3 macam yaitu maca, ngaji lan macul. Manusia bisa memilih salah satu ataupun semuanya. Tetapi bila memilih, harus konsisten tekun dan jujur. Kejujuran dan kebenaran harus dijunjung tinggi. Di duania ini yang rawan dengan kejujuran adalah pedagang, maklar atau blantik dan kemasan (pembuat perhiasan dari emas).

Menjauhi perbuatan tercela, terutama ma lima, harus dihindari. Dalam Serat Wulang Sunu bukan hanya ma lima tetapi ma 8 . berkaitan dengan hal tersebut, pengarang menjelaskan bahwa dalam diri kita bertahta empat orang 
raja. Dua orang ratu, perempuan cantik bergelar ratu Mutmainah. la bertahta di jantung. Bila keluar melalui hidung. Pakaiannya putih bersih, jujur dan pemaaf. Kedua ratu Supiah. la memakai pakaina sutra kuning, suka bersolek, dan banyak keinginan. la bertahta dalam alat kelamin. Bila keluar melalui mata. Oleh sebab itu, seseorang bila melihat sesuatu yang indah, lantas ingin memiliki.

Sedangkan dua orang raja, raja Amarah dan Aluamah. raja Amarah pakaiannya serba merah, bertahta dalam dada, keluar melalui telinga. Sang raja sangat kuat. Bala tentaranya sangat banyak, seperti angkuh, sombong, jail, butarepan dll. Sedangkan raja aluamah bertahta dalam perut (waduk) bila keluar lewat pintu gerbang utama (mulut), Pakaiannya serba hitam. Sang raja senang makan dan tidur. la banyak makan dan sangat ambisius.

\section{DAFTAR RUJUKAN}

Baried, Siti Baroroh, 1994. Pengantar Teori Filologi. Yogyakarta: FS UGM.

Behrend. T.E. 1999. Katalog Induk Naskah-Naskah Nusantara. Museum Sanabudaya, Yogyakarta. Jl. I . Jakarta. Jambatan.

Darusuprapta. 1980. Diktat Materi Kuliah Sastra Jawa Kuna. Yogyakarta. FSK. UGM.

Gonda, J. Dr. 1934. Een Oud Javaansche Prozageschrift Agastyaparwa. s'Gravenhage, Martinus, Nijhoff.

Djamaris, Edward, 1987 . "Filologi dan Cara Kerja Penelitian Filologi" Bahasa dan Sastra III. Jakarta: Pusat Pembinaan dan Pengembangan Bahasa.

Kamidjan. 2012. Serat Harda Mudha dalam Kesusasteraan Jawa: Kajian Struktur, Fungsi, dan Makna. Universitas Udayana. Disertasi.

Novalia Herawati, Vivin. 2010. Nilai-Nilai Moral dalam Serat Wulang Sunu. Skripsi. FBS Unesa Surabaya.

Padmosoekotjo. S 1952. Ngengrengan Kasusastran Djawa. Jl. II. Yogyakarta: Hien Hoo Sing.

Poerbatjaraka. R. Ng. 1967. Kapustakan Jawi. Penerbit. Obor. Djakarta. 
Kamidjan, Naskah Serat Wulang Sunu...(hal. 116 - 239)

Poespoprodjo.W. 1987. Interpretasi. Bandung. CV. remaja Karya.

Pigeaud, Th.G. 1967. Literature of Java. I. The Hague, Martinus. Nijhoff.

Prawiraatmadja, S. 1980. Bausastra Jawa. Surabaya, Citra Jaya Murti.

Robson, SO,1987. "Pengkajian Sastra Tradisional Indonesia." Bahasa dan Sastra. No.6. th.IV. Jurnal. Jakarta: Gramedia.

Suprayitno. Sumarti. 1983. Slokantara. Sebuah Sastra Didaktik Jawa kuna. Yogyakarta. Proyak Javanologi.

Teeuw, A. 1980. "Filologi Sebagai Cabang Ilmu Sastra" Makalah. UGM Yogyakarta.

Zoetmulser, 1983. Kalangwan, sastra Jawa Kuna Selayang Pandang, Terjemahan Dick. Hartoko. Jakarta Jambatan. 